\title{
LETTERS
}

\section{Family Caregivers, Patients, and Physicians}

\author{
Jennifer L. Wolff, PhD and Debra L. Roter, DrPH
}

Johns Hopkins University, Baltimore, MD, USA.

To the Editors:-The position paper "Family Caregivers, Patients, and Physicians: Ethical Guidance to Optimize Relationships" that was published in a recent issue of the Journal raises an important topic. We read the paper with great interest and agree with its stated objective to "heighten physician awareness of the importance and complexity of the patient-physician-family caregiver relationship, to maximize the benefits of those relationships, and to minimize the burdens on family caregivers".

To this end, we were surprised to note the omission of more than a few studies of central relevance (e.g. Petronio, S., J. Sargent, L. Andea, P. Reganis, and D. Cichocki. 2004. Family and friends as healthcare advocates: Dilemmas of confidentiality and privacy. Journal of Social and Personal Relationships 21: 33-52.). We recently completed a meta-analysis of empirical studies reporting on family presence during routine adult medical visits in which we identified nine observational studies that directly examined audiotaped or videotaped patientprovider-family communication within the context of routine medical visits, and an additional six studies that surveyed patients, families, and/or physicians regarding their experiences and preferences for family involvement in routine adult medical visits; only one of which was cited in the position paper. These studies collectively provide important information regarding the frequency of patient accompaniment, the behaviors assumed by family companions, as well as patient, family, and physician preferences, expectations, and experiences during triadic physician visits. The recommendations set forth in this paper would be strengthened if they acknowledged what has already been learned and reported in the published literature.

We would also like to note that the term "family caregiver" used throughout the paper, which the authors define as "relatives, partners, friends, and neighbors who assist with activities of daily living and complex health care needs that were once the domain of trained health hospital personnel" may not accurately describe all individuals who accompany patients during health care encounters. Although some family members who accompany patients to health care encounters also engage in the provision of personal and health care assistance to the patients they accompany, there is reason to believe this is not always the case. The extent to which the family members who accompany patients during health care encounters also assist with health care and personal tasks in the community is an important question that to our knowledge has been unstudied to date.

Jennifer L. Wolff, PhD; Johns Hopkins University, $624 \mathrm{~N}$. Broadway, Baltimore, MD 21205, USA (e-mail: jwolff@jhsph.edu).

$\mathrm{J}$ Gen Intern Med 25(6):487

DOI: $10.1007 / \mathrm{s} 11606-010-1314-0$

( ) Society of General Internal Medicine 2010

Published online March 19, 2010 